\title{
Regional and Volumetric Parameters for Diffusion-Weighted WHO Grade II and III Glioma Genotyping: A Method Comparison
}

\author{
(D) S.C. Thust, (D).A. Maynard, (D) M. Benenati, (D) S.J. Wastling, (D) L. Mancini, (D) Z. Jaunmuktane, (D). Brandner, and (DH.R. Jäger
} O- $=$

\begin{abstract}
BACKGROUND AND PURPOSE: Studies consistently report lower ADC values in isocitrate dehydrogenase (IDH) wild-type gliomas than in IDH mutant tumors, but their methods and thresholds vary. This research aimed to compare volumetric and regional ADC measurement techniques for glioma genotyping, with a focus on IDH status prediction.
\end{abstract}

MATERIALS AND METHODS: Treatment-naïve World Health Organization grade II and III gliomas were analyzed by 3 neuroradiologist readers blinded to tissue results. ADC minimum and mean ROIs were defined in tumor and in normal-appearing white matter to calculate normalized values. T2-weighted tumor VOls were registered to ADC maps with histogram parameters (mean, 2nd and 5th percentiles) extracted. Nonparametric testing (eta ${ }^{2}$ and ANOVA) was performed to identify associations between ADC metrics and glioma genotypes. Logistic regression was used to probe the ability of VOI and ROI metrics to predict IDH status.

RESULTS: The study included 283 patients with 79 IDH wild-type and 204 IDH mutant gliomas. Across the study population, IDH status was most accurately predicted by ROI mean normalized ADC and VOI mean normalized ADC, with areas under the curve of 0.83 and 0.82 , respectively. The results for ROI-based genotyping of nonenhancing and solid-patchy enhancing gliomas were comparable with volumetric parameters (area under the curve $=0.81-0.84)$. In rim-enhancing, centrally necrotic tumors $(n=23)$, only volumetric measurements were predictive $(0.90)$.

CONCLUSIONS: Regional normalized mean ADC measurements are noninferior to volumetric segmentation for defining solid glioma IDH status. Partially necrotic, rim-enhancing tumors are unsuitable for ROI assessment and may benefit from volumetric ADC quantification.

ABBREVIATIONS: $\mathrm{AUC}=$ area under the curve; $\mathrm{NAWM}=$ normal-appearing white matter; min $=$ minimum; 1 1919 $q^{\text {codel }}=$ codeletion of the short arm of chromosome 1 and the long arm of chromosome 19; rADC = normalized ADC; WHO = World Health Organization

D iffuse gliomas of World Health Organization (WHO) grades II and III comprise a diverse group of tumors characterized by distinct genetic profiles and varied median survival. ${ }^{1}$ Three major types of diffuse gliomas are found in adults: isocitrate

Received July 11, 2020; accepted after revision October 19.

From the Neuroradiological Academic Unit (S.C.T., J.A.M., S.J.W., L.M., H.R.J.), Department of Brain, Repair and Rehabilitation, UCL Institute of Neurology, London, UK; Lysholm Department of Neuroradiology (S.C.T., J.A.M., M.B., S.J.W., L.M., H.R.J.), National Hospital for Neurology and Neurosurgery, London, UK; Imaging Department (S.C.T., H.R.J.), University College London Foundation Hospital, London, UK; Dipartimento di Diagnostica per Immagini (M.B.), Radioterapia, Oncologia ed Ematologia, Fondazione Policlinico Universitario A. Gemelli Institute for Research, Hospitalization and Health Care, Rome, Italy; and Departments of Clinical and Movement Neurosciences (Z.J.), and Neurodegenerative Disease (S.B.), UCL Queen Square Institute of Neurology, and Division of Neuropathology, National Hospital for Neurology and Neurosurgery, University College London Hospitals NHS Foundation Trust, London, UK.

S.C. Thust, Z. Jaunmuktane, and S. Brandner are supported by the Department of Health's National Institute of Health Research/Biomedical Research Center's funding scheme to the University College London Hospitals. No specific grant is associated with this research.

S.C. Thust, J.A. Maynard, and M. Benenati contributed equally to this work. dehydrogenase $(I D H)$ wild-type gliomas with a molecular profile of $I D H$ wild-type glioblastoma, $I D H$ mutant astrocytoma (with p53 and ATRX chromatin remodeler $[$ ATRX] mutations), and the $I D H$ mutant oligodendroglioma with a codeletion of the short arm of chromosome $1 p$ and the long arm of chromosome $19 q$ (IDH mutant $\left./ 1 \mathrm{p} 19 \mathrm{q}^{\text {codel }}\right){ }^{2}$ In addition to these major intrinsic neoplasms, multiple other tumor types exist, for example, with alterations in the map kinase pathway (B-Raf proto-oncogene, serine/threonine kinase $[B R A F]$ mutations), histone mutations, and the distinct group of ependymal tumors.

$I D H$ wild-type astrocytomas share glioblastoma-specific genetic mutations such as combined chromosome 7 gain and

Please address correspondence to Stefanie Thust, MD, FRCR, Lysholm Department of Neuroradiology, National Hospital for Neurology and Neurosurgery, Queen Square, London WCIN 3BG, UK; e-mail: s.thust@ucl.ac.uk

- Indicates open access to non-subscribers at www.ajnr.org

Indicates article with online supplemental data.

http://dx.doi.org/10.3174/ajnr.A6965 
chromosome 10 loss, epidermal growth factor receptor (EGFR) amplification, and/or telomerase reverse transcriptase (TERT) promoter mutations ${ }^{3}$ and have a short life expectancy., Henceforth, with the term "IDH wild-type diffuse glioma," we will refer to molecular glioblastoma, $I D H$ wild-type.

Rapid glioma genotyping is of prognostic importance and influences therapeutic planning; for example, IDH mutant/ $1 \mathrm{p} 19 \mathrm{q}^{\text {codel }}$ gliomas are responsive to chemotherapy, ${ }^{5}$ whereas in $1 \mathrm{p} 19 \mathrm{q}$ intact (IDH mutant/1p19q intact) tumors, maximum safe resection appears critical to improve outcomes. ${ }^{6}$ It remains uncertain to what extent the strategy of maximal glioblastoma resection $^{7,8}$ could prolong survival for diffusely infiltrative $I D H$ wild-type gliomas in the WHO grade II and III stages.

A number of imaging techniques have shown the potential for glioma genotype predictions. Of these, conventional MR imaging has the advantage of universal availability, but mostly provides visual-anatomic features, some of which have limited reproducibility. ${ }^{9,10}$ Advanced MR imaging techniques such as perfusion and spectroscopy provide physiologic, quantifiable tumor data but can have threshold overlap and lack of technical standardization. ${ }^{11}$

DWI is widely integrated into clinical glioma MR imaging protocols with tissue properties measurable at the time of reporting. DWI exploits the inverse relationship between free water motion in tissues and cellularity. ${ }^{12}$ Differences in diffusionweighted image signals have been shown for glioma WHO grades and, more recently, between genetic subtypes. ${ }^{13,14}$ The finding of lower ADC values in $I D H$ wild-type diffuse glioma compared with $I D H$ mutant tumors is consistently reported; however, the methods and accuracy vary among studies, whereby published techniques include mean and minimum ROI measurements and, in some cases, volumetric ADC quantification. ${ }^{13-16}$ Hypothetically, "entire lesion" analysis might provide the most representative information on any individual tumor, whereas ROI placements have the advantage of being minimally time-consuming in clinical workflow.

There are few data comparing regional and volumetric diffusivity measurements for glioma genotyping, currently limited to nonenhancing glioma evaluation. The purpose of this study was to compare the performance of whole-tumor ADC measurements with different ROI parameters for glioma molecular typing, with a focus on $I D H$ status prediction.

\section{MATERIALS AND METHODS}

\section{Patients}

Ethics review board approval (University College London Hospitals and Health Research Authority, United Kingdom) was obtained with informed consent waived for this retrospective imaging data study. Consecutive patients diagnosed at our national brain tumor referral institution from July 2008 to January 2018 were eligible for the research.

Inclusion criteria consisted of histologic confirmation of WHO grade II and III glioma, documented IDH and $1 \mathrm{p} 19 \mathrm{q}$ genetic test results, and available pretreatment MR imaging. Exclusion criteria were previous glioma treatment; a diagnosis other than WHO grade II and III gliomas; incomplete, inconclusive, or ambiguous molecular results (eg, $I D H$ wild-type/1p19q ${ }^{\text {codel }}$ ); a prolonged ( $\geq$ year) interval from MR imaging to surgery; incomplete images; and failed volumetric image registration.

All tissue samples were analyzed at our neuropathology department, using the latest methodology according to the WHO 2016 Classification of CNS Tumors, as described previously. ${ }^{17,18}$ Multiple gene Sanger sequencing was completed for IDH R132Hnegative tumors to identify rarer $I D H$ mutations, and the $1 \mathrm{p} / 19 \mathrm{q}$ status was established through quantitative polymerase chain reaction-based copy number assay.

\section{MR Imaging Acquisition and Postprocessing}

All MR imaging examinations included T2-weighted, T2-FLAIR, and T1-weighted sequences; pre- and postadministration of a gadolinium-based contrast agent; and DWI sequences $(n=211$ at $1.5 \mathrm{~T}, n=79$ at $3 \mathrm{~T}$ ). Because our institution is a quaternary center, the imaging originated from 23 different MR imaging machines with no individual scanner contributing $>14 \%$ of any glioma subtype. In the generation of an ADC map, the image acquired without diffusion gradients is divided by the image acquired with diffusion gradients, removing dependence on T1, T2, and TR. ${ }^{19}$ Sufficient comparability of ADC among scanners has been demonstrated previously. ${ }^{20}$ The range of MR imaging parameters used has been described in a prior component of the study. $^{21}$ ADC maps were calculated from 3-directional DWI acquired with 2 gradient values $\left(b=0\right.$ and $b=1000 \mathrm{~s} / \mathrm{mm}^{2}$ ) using proprietary software (Olea Sphere, Version 2.3; Olea Medical).

\section{ROI Measurements}

The ADC regional measurements were performed by 3 independent observers as detailed in Maynard et al, ${ }^{21}$ blinded to tissue diagnosis. First, each observer sited small $\left(30-40 \mathrm{~mm}^{2}\right)$ ROIs $3 \times$ into the visually perceived lowest ADC portions of each glioma (within $\geq 1$ axial image slice), while remaining in the solid tumor component and avoiding apparent necrotic, hemorrhagic, or cystic areas or blood vessels, as identified on the relevant accompanying contrast-enhanced and other sequences. From these 3 ROIs, the mean value of the numerically lowest ADC measurement was designated minimum $\mathrm{ADC}\left(\mathrm{ADC}_{\mathrm{min}}\right)$ as described in Xing et al. ${ }^{14}$

Thereafter, 1 large ROI ( $\mathrm{ADC}_{\text {mean }}$ ) was placed to cover most of the largest axial tumor cross-section, excluding tumor margins, necrosis, macroscopic hemorrhage, and calcifications, as described in Thust et al. ${ }^{22}$ Finally, a comparative ROI was positioned in the contralateral normal-appearing centrum semiovale white matter $\left(\mathrm{ADC}_{\mathrm{NAWM}}\right)$, amounting to 5 ROI measurements per patient. Multifocal tumors were measured as 1 glioma.

Observer 1 analyzed all $(n=290)$ gliomas, observer 2 re-analyzed a subset of 75 gliomas, and observer 3 re-analyzed the remaining subset of 215 gliomas, totaling 2900 ADC measurements (ie, 5 ROIs by 2 observers per glioma, ie, $10 \times 290$ measurements). From these, the normalized minimum ADC ( $\mathrm{rADC}_{\text {min }}$, defined as $\mathrm{ADC}_{\mathrm{min}} / \mathrm{ADC}_{\mathrm{NAWM}}$ ratio) and the mean normalized $\mathrm{ADC}\left(\mathrm{rADC}_{\text {mean }}\right.$ ) (defined as $\mathrm{ADC}_{\text {mean }} / \mathrm{ADC}_{\mathrm{NAWM}}$ ratio) were calculated, resulting in 4 regional $\mathrm{ADC}$ parameters (ROI $\mathrm{ADC}_{\text {min }}$, ROI $\mathrm{rADC}_{\text {min, }}$ ROI $\mathrm{ADC}_{\text {mean }}$ and ROI 


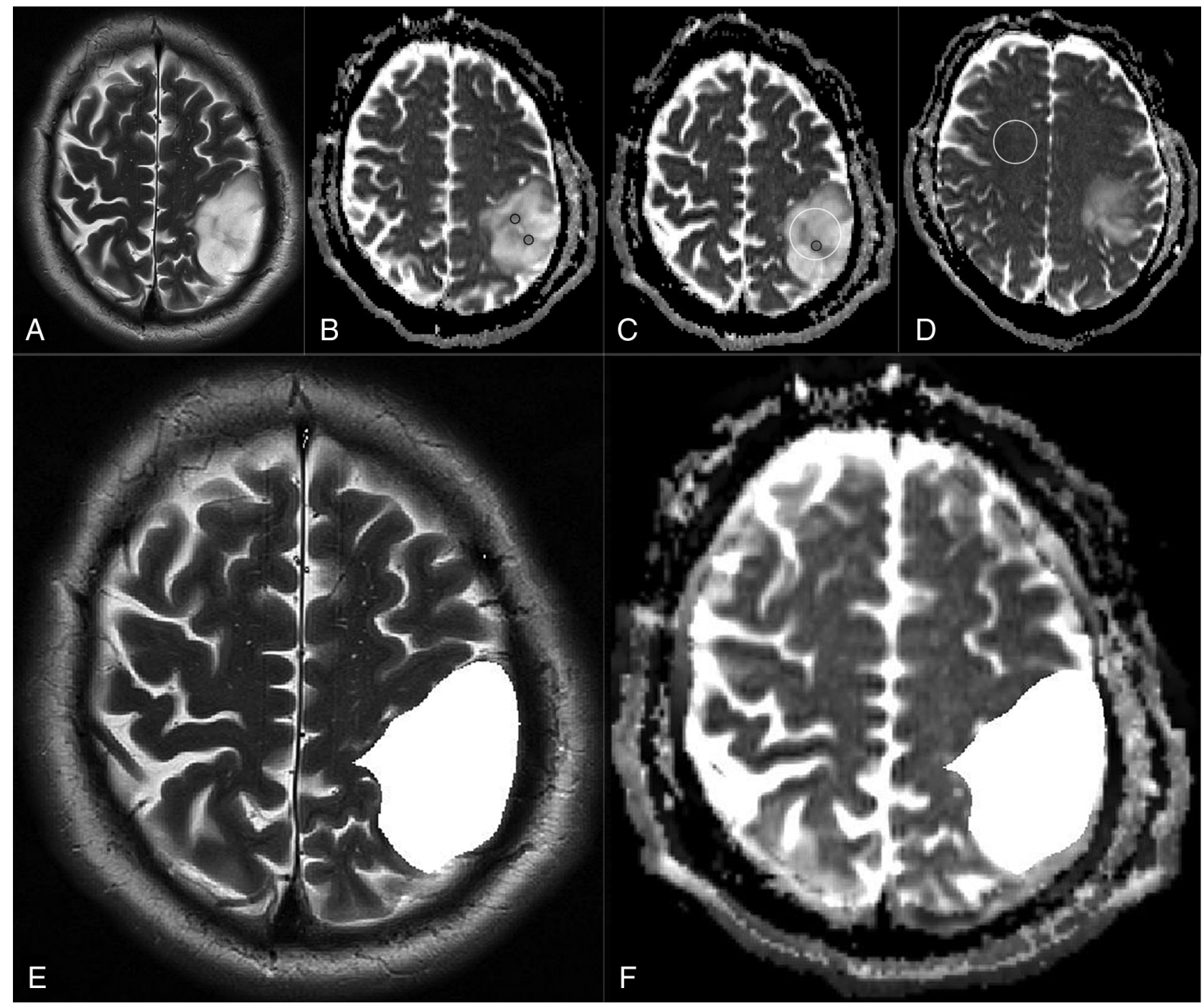

FIG 1. An example of regional and volumetric $A D C$ measurements in a patient with IDH mutant 1p19q intact glioma. T2-weighted image $(A)$ and $A D C$ maps $(B-D)$ show $A D C_{\text {min }}\left(3 \times 30-40 \mathrm{~mm}^{2}\right.$ (black, $B$ and $C$ ), $A D C_{\text {mean }}$ (white, $C$ ), and $A D C_{\text {NAWM }}$ (white, $\left.D\right)$ ROI measurements. T2-weighted image $(E)$ and $A D C$ map $(F)$ in the same patient demonstrate the volumetric segmentation and image registration, respectively.

$\left.\mathrm{rADC}_{\text {mean }}\right)$ per glioma. An example of the ROI placements is shown in Fig $1 A-D$.

\section{Volumetric ADC Histogram Analysis}

Whole-tumor VOIs were segmented by a general radiologist (M.B., 5 years' experience) using the ITK-Snap Toolbox, Version 3.6 (www.itksnap.org ${ }^{23}$ ) following training and under supervision of a neuroradiologist specialized in brain tumor imaging (S.C.T, 9 years' experience). Segmentations incorporated the entire T2-weighted signal abnormality. For multicentric gliomas, the total volume of signal abnormality was treated as 1 lesion. To assess interobserver reproducibility, a proportion (10\%) of gliomas was randomly chosen to undergo a repeat unsupervised segmentation by a second neuroradiologist (J.A.M., 4 years' experience, including brain tumor research).

ADC maps were then co-registered to T2-weighted sequences using the FMRIB Linear Image Registration Tool (FLIRT; http:// www.fmrib.ox.ac.uk/fsl/fslwiki/FLIRT), ${ }^{24,25}$ according to an affine 12-parameter model with the correlation ratio as a cost function, except in 15 cases in which manual review favored optimization of the registration by substitution of Normalized Mutual Information as the cost function. Subsequently, ADC histogram data were obtained for each tumor ROI, using an in-house script written in Python 2.7. For each tumor, the second and fifth ADC histogram percentiles, ADC mean, and the T2-weighted total lesion volume were extracted. Normalized histogram parameters were calculated using the same ROI $\mathrm{ADC}_{\mathrm{NAwM}}$ value for the regional measurements to maximize direct comparability. An example of the volumetric segmentation is provided in Fig $1 E,-F$.

\section{Enhancement Pattern Subgroup Analysis}

Information on tumor enhancement, recorded as part of a preceding study, ${ }^{21}$ was used for a subgroup analysis. Thus, the ability of ROI and VOI parameters to predict the IDH genotype was assessed separately for 3 morphologic groups: 1) nonenhancing, 2) solid-patchy enhancing, and 3) rimenhancing, centrally necrotic gliomas. An example of the enhancement pattern distinction is provided in the Online Supplemental Data. 


\begin{tabular}{lllll}
\hline & $\begin{array}{c}\text { All Glioma } \\
\text { Subtypes }\end{array}$ & $\begin{array}{c}\text { IDH } \\
\text { Wild-Type }\end{array}$ & $\begin{array}{c}\text { IDH Mutant/ } \\
\text { 1p19q Intact }\end{array}$ & $\begin{array}{c}\text { IDH Mutant/ } \\
\text { Ip19q }\end{array}$ \\
\hline No. of patients = 283 (male/female =164:119) & 283 & 79 & 104 & 100 \\
Median age (interquartile range) (yr) & $40(33-53)$ & $59(43-67)$ & $35(29-41)$ & $40(35-48)$ \\
Enhancement category & & & & \\
Nonenhancing & 171 & 33 & 75 & 63 \\
Solid-patchy enhancing & 87 & 28 & 27 & 32 \\
Rim-enhancing & 23 & 18 & 0 & 5 \\
\hline
\end{tabular}

Note:-1p19q ${ }^{\text {codel }}$ indicates codeletion of the short arm of chromosome 1 and the long arm of chromosome 19.

${ }^{a}$ In 2/283 patients, T1-weighted contrast-enhanced MR images were unavailable.

\section{Statistical Analysis}

All statistical testing was performed in SPSS 25 (IBM). The interobserver agreement for the ROI-derived ADC measurements and for the volumetric segmentations was assessed by intraclass correlation coefficient analysis, using a 2-way random effects model. For each ADC ROI, the mean of the observers' measurements was adopted as the final value. For the proportion of tumors that were segmented by 2 observers, the average of the volumetric $\mathrm{ADC}$ results was designated as the final value.

To compare the mean ranks of the groups of ADC values and glioma subtypes, we used the nonparametric Kruskal-Wallis ANOVA test, including the Dunn pair-wise comparisons with Bonferroni correction. The strength of the association between glioma subtype and ADC metrics was tested using eta ${ }^{2}\left(\eta^{2}\right)$, which quantifies the percentage of variance in the dependent variable (ADC value) that is explained by $>1$ independent variable (glioma genotype).

Univariable logistic regression was applied to test which ROI or VOI ADC parameter best predicted glioma IDH status (with $P<.05$ considered significant). The Youden index was used to identify diagnostic thresholds for the most predictive parameter, as determined by the area under the curve (AUC). Nonparametric (Wilcoxon signed rank) testing was performed to assess differences between the region-derived and volumetric ADC values.

\section{RESULTS}

\section{Patient Demographics}

Of 515 patients identified as potentially eligible for the study, 42 were duplicates, and 190 met the exclusion criteria as follows: previous glioma treatment $(n=60)$, tumor other than WHO grade II or III glioma ( $n=43$ and $n=1$ spinal cord tumor), ambiguous or incomplete molecular results $(n=29)$, no preoperative DWI $(n=$ 24 and $n=15$ ADC maps not computable), unavailable histopathology report $(n=2)$, prolonged ( $\geq 1$ year) interval from MR imaging to surgery $(n=3)$, MRI artefact $(n=5)$, incomplete images $(n=1)$, and failed volumetric image registration $(n=7)$. Finally, 283 patients (median, 40 years of age; interquartile range, 33-53 years; 164 men) were included in the analysis. The demographic details for the study population are listed in the Table.

\section{Observer Comparison}

The reproducibility of the ROI ADC parameters and contrastenhancement patterns among 3 independent raters has been established in preceding research (intraclass correlation coefficient $=0.83-0.96$ and Cohen $\kappa=0.69-0.72$, respectively). ${ }^{21}$ In the current study, the concordance between the 2 observers for the twice-segmented tumor volumes $(n=28)$ was near-complete (intraclass correlation coefficient $=0.97-0.98$ ). This information is further detailed in the Online Supplemental Data.

\section{Association between ADC Values and IDH Genotype}

Box and whisker plots showing a comparison between IDH mutant and $I D H$ wild-type gliomas for $\mathrm{ADC}_{\text {mean }}, \mathrm{rADC}_{\text {mean }}$, $\mathrm{ADC}_{\text {min }}$, and $\mathrm{rADC}_{\text {min }}$ are shown in the Online Supplemental Data (VOI and ROI methods). Detailed results from the statistical analysis with Kruskal-Wallis and $\eta^{2}$ tests are provided in the Online Supplemental Data. For all regional parameters (ROI $\mathrm{ADC}_{\text {min }}, \mathrm{ROI} \mathrm{rADC}_{\text {min }}$, ROI $\mathrm{ADC}_{\text {mean }}$, and ROI $\mathrm{rADC}_{\text {mean }}$ ), the ADC values significantly differed among the $I D H$ wild-type, $I D H$ mutant, $1 \mathrm{p} 19 \mathrm{q}$ intact, and $I D H$ mutant $1 \mathrm{p} 19 \mathrm{q}^{\text {codel }}$ glioma groups $(P<.001)$. VOI $\mathrm{ADC}_{\text {mean }}$ and $\mathrm{VOI} \mathrm{rADC}_{\text {mean }}$ also differed among the glioma molecular groups $(P<.001)$.

VOI $\mathrm{ADC}_{\text {min }}$ and VOI $\mathrm{rADC}_{\text {min }}$ differed between $I D H$ wildtype and $I D H$ mutant $1 \mathrm{p} 19 \mathrm{q}^{\text {codel }}$ genotypes $(P=.003$ and $P<.001$, respectively). However, no significant difference in VOI $\mathrm{ADC}_{\text {min }}$ or VOI $\mathrm{rADC}_{\text {min }}$ was shown between $\mathrm{IDH}$ mutant $1 \mathrm{p} 19 \mathrm{q}$ intact and $I D H$ mutant $1 \mathrm{p} 19 \mathrm{q}^{\text {codel }}$ gliomas.

Wilcoxon signed rank testing confirmed statistically significant differences between the VOI and ROI results of the absolute and normalized ADC values $(P<.001)$. The association between glioma genotype and diffusivity was strongest for $\mathrm{ROI} \mathrm{ADC}_{\text {mean }}$ and ROI rADC mean $_{\text {values }}\left(\eta^{2}=0.38\right)$ across the study population, while also being substantial for $\mathrm{ROI} \mathrm{ADC}_{\min }$ and $\mathrm{ROI}$ $\operatorname{rADC}_{\min }\left(\eta^{2}=0.28-0.29\right)$.

The subgroup analysis according to the contrast-enhancement pattern revealed associations between $\mathrm{ROI} \mathrm{ADC}_{\text {mean }}$ and $\mathrm{ROI}$ $\mathrm{rADC}_{\text {mean }}$ values and genotype for nonenhancing gliomas $(n=$ $\left.170, \eta^{2}=0.39-0.41\right)$ and solid-patchy enhancing gliomas $(n=$ $\left.85, \eta^{2}=0.24-0.28\right)$. No association was evident between ROI ADC parameters and the rim-enhancing, centrally necrotic glioma IDH genotype ( $\left.n=23, \eta^{2}=0.0-0.05\right)$. The strongest association for the rim-enhancing gliomas was with $\mathrm{VOI} \mathrm{rADC}_{\text {mean }}$ values $\left(\eta^{2}=0.36\right)$.

No correlation among $\mathrm{IDH}$ status, VOI $\mathrm{ADC}_{\min }$, and VOI $\mathrm{rADC}_{\text {min }}$ was identified for nonenhancing gliomas $\left(\eta^{2}=0.02-\right.$ 0.03). Across all regional and volumetric parameters, smaller $\eta^{2}$ effect sizes were observed for minimum ADC values compared with mean $\mathrm{ADC}$ values. The $\mathrm{VOI} \mathrm{ADC}_{\text {min }}$ was tested as determined by either the 2nd or 5th percentile by histogram analysis, with consistently larger $\eta^{2}$ values observed between $\mathrm{ADC}_{\text {min }}$ and genotype when the 5th percentile was used. Thereafter, VOI $\mathrm{ADC}_{\text {min }}$ referred to the 5 th percentile only. 


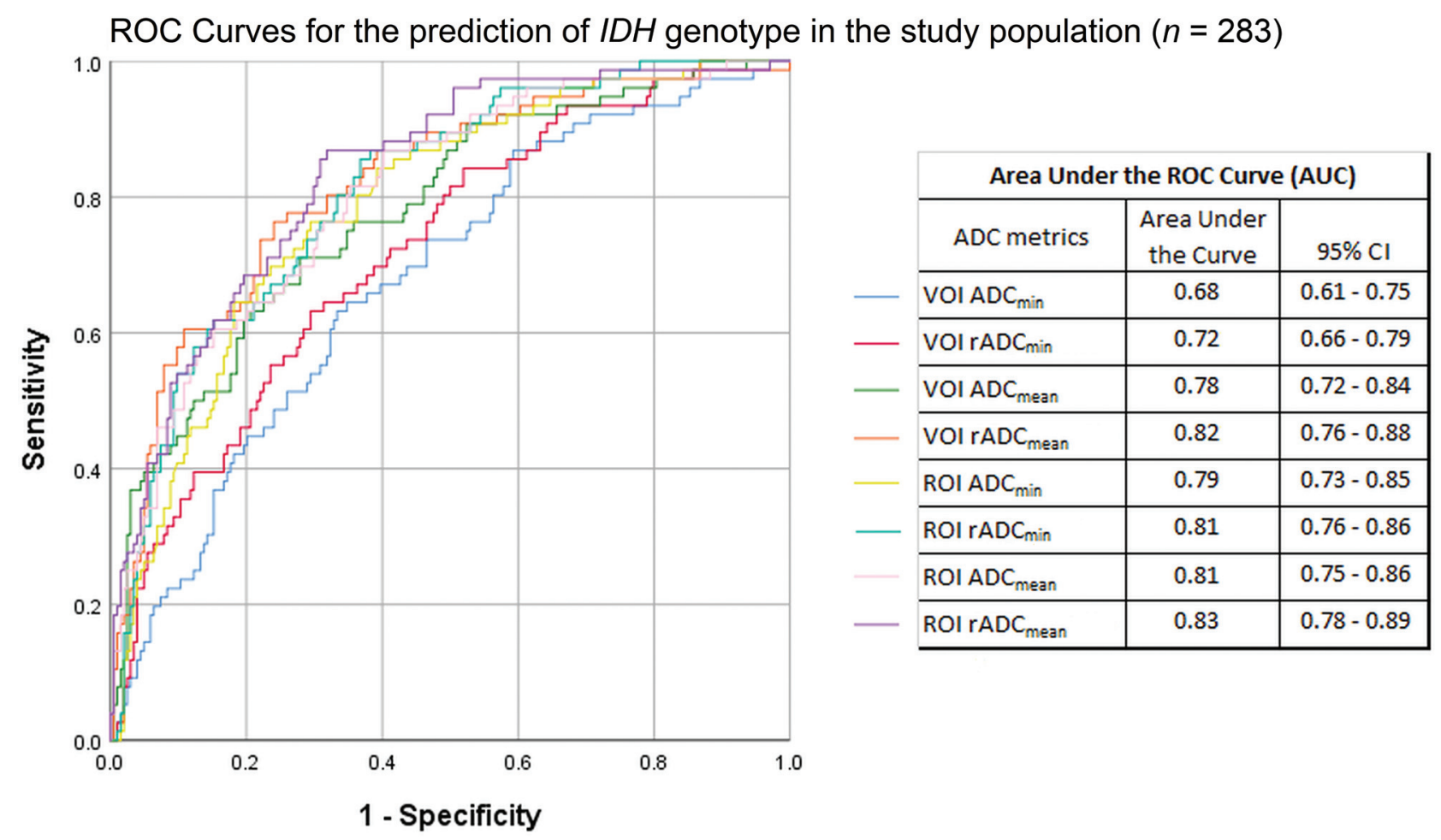

FIG 2. ROC curves for the prediction of IDH genotype in the study population $(n=283)$.

\section{Univariable Analysis for Prediction of IDH Status}

The univariable analysis of regional and volumetric ADC metrics, when compared across all $(n=283)$ gliomas, showed that the most accurate prediction of $I D H$ status was achieved using ROI $\mathrm{rADC}_{\text {mean }}$ or VOI $\mathrm{rADC}_{\text {mean }}(\mathrm{AUC}=0.83$ and 0.82 , respectively). The least accurate predictions were observed for $\mathrm{VOI}$ $\mathrm{ADC}_{\text {min }}(\mathrm{AUC}=0.68)$ and $\mathrm{VOI} \mathrm{rADC}_{\min }(\mathrm{AUC}=0.72)$. The ROC curve analysis is presented in Fig 2, with additional results listed in the Online Supplemental Data.

When assessing nonenhancing gliomas alone, the ROI $\mathrm{ADC}_{\text {mean }}(\mathrm{AUC}=0.82)$ and $\mathrm{ROI} \mathrm{rADC}_{\text {mean }}(\mathrm{AUC}=0.84)$ results were almost equal to the $\mathrm{VOI} \mathrm{ADC}_{\text {mean }}(\mathrm{AUC}=0.81)$ and VOI $\mathrm{rADC}_{\text {mean }}(\mathrm{AUC}=0.84)$. For solid-patchy tumors, the $\mathrm{ROI} \mathrm{ADC}_{\text {mean }}(\mathrm{AUC}=0.79)$ and $\mathrm{ROI} \mathrm{rADC}_{\text {mean }}(\mathrm{AUC}=0.81)$ were almost equal to the $\mathrm{VOI} \mathrm{ADC}_{\text {mean }}(\mathrm{AUC}=0.78)$ and $\mathrm{VOI}$ $\mathrm{rADC}_{\text {mean }}(\mathrm{AUC}=0.80)$, respectively.

Conversely, in rim-enhancing centrally necrotic lesions, only volumetric $\mathrm{ADC}$ results demonstrated a significant ability to predict $I D H$ status $\left(\mathrm{VOI} \mathrm{ADC}_{\text {mean }}\right.$ [AUC $\left.=0.84\right]$, VOI $\mathrm{rADC}_{\text {mean }}$ [AUC $=0.90]$, but not the ROI $\mathrm{ADC}_{\text {mean }}$ and $\mathrm{ROI} \mathrm{rADC}_{\text {mean }}$ values (AUC $=0.49-0.61$ ). Given the lack of an association between the volumetric $\mathrm{ADC}_{\text {min }}$ parameters and $\mathrm{IDH}$ status, these were not further subjected to a subgroup analysis according to enhancement patterns.

\section{DISCUSSION}

This study investigated the comparability of region-derived and volumetric ADC values for WHO grade II and III glioma genotyping, specifically their performance for predicting $I D H$ status. Our results indicate that the accuracy of regional measurements for solid glioma $I D H$ typing is unimproved by performing wholetumor segmentations (maximum AUC $=0.84$ for VOI and ROI $\left.\mathrm{rADC}_{\text {mean }}\right)$. However, for $I D H$ status prediction in the small proportion of rim-enhancing, centrally necrotic tumors $(n=23)$, entire lesion ADC mean parameters were superior to solid-tumor ROI measurements. Throughout the study, mean ADC measurements appeared more accurate than $\mathrm{ADC}_{\text {min }}$ metrics, particularly if performing a volumetric analysis.

Before the discovery of glioma molecular subgroups, research was focused on testing the ability of ADC to predict glioma histologic grades, showing an inverse correlation between cellularity and diffusion. ${ }^{26-28}$ More recently, Leu et $\mathrm{al}^{13}$ demonstrated a stronger association between glioma ADC values and genotype than WHO grade. Specifically for $I D H$ wild-type glioblastoma, no difference in diffusivity may exist between grades II and IV. ${ }^{29}$ Villaneuva-Meyer et $\mathrm{al}^{30}$ previously assessed ROI-derived minimum, mean, and maximum in WHO grade II gliomas: A minimum ADC threshold of $0.9 \times 10^{-3}$ seconds $/ \mathrm{mm}^{2}$ provided the greatest sensitivity (91\%) and specificity (76\%) for IDH typing, with an AUC of $0.901 .{ }^{19}$ ROI-based minimum ADC analysis was also performed by Wasserman et $\mathrm{al}^{15}$ with a proposed cutoff point of $0.95 \times 10^{-3}$ seconds $/ \mathrm{mm}^{2}$ (sensitivity of $76.9 \%$, specificity of $65.2 \%$, and $\mathrm{AUC}=0.711)^{13}$ and by Xing et $\mathrm{al}^{14}$ with a suggested minimum ADC threshold of $1.01 \times 10^{-3}$ seconds $/ \mathrm{mm}^{2}$ (sensitivity of $76.9 \%$, specificity of $82.6 \%$, AUC $=0.87) .{ }^{15}$

By means of ROI measurements, $\mathrm{ADC}_{\text {min }}$ and $\mathrm{rADC}_{\text {min }}$ appeared valuable for $I D H$ typing in our study, with optimal thresholds in the region of $1.07 \times 10^{-3 \text { seconds }} / \mathrm{mm}^{2}$ (sensitivity of $82.3 \%$, specificity of $61.3 \%$, AUC $=0.79$ ) and 1.40 (sensitivity of $85.5 \%$, specificity of $62.3 \%, \mathrm{AUC}=0.81$ ), respectively. For an ROI $\mathrm{ADC}_{\text {mean }}$ threshold of $1.34 \times 10^{-3}$ seconds $/ \mathrm{mm}^{2}$, a similar 
sensitivity of $84.8 \%$, specificity of $60.3 \%$, and AUC of 0.81 were observed. For an $\mathrm{rADC}_{\text {mean }}$ threshold of 1.75 , the results were marginally better (sensitivity of $86.8 \%$, specificity of 62.3, AUC $=$ $0.83)$.

Across the whole study population, the largest ROI AUC (0.83) was observed for $\mathrm{rADC}_{\text {mean }}$ values in our research. Liu et $\mathrm{al}^{16}$ previously assessed glioma mean and minimum ADC, but only the results for mean ADC reached statistical significance $(P=.028)$. Recently, in a study of normalized mean measurements for $I D H$ typing of non-gadolinium-enhancing WHO grades II and III gliomas, an $\mathrm{rADC}_{\text {mean }}$ threshold in the region of 1.8 was proposed. $^{22}$

Several studies reported lower ADC values in $I D H$ mutant $1 \mathrm{p} 19 \mathrm{q}^{\text {codel }}$ oligodendrogliomas compared with IDH mutant $1 \mathrm{p} 19 \mathrm{q}$ intact astrocytomas, with 2 studies indicating an $\mathrm{ADC}_{\text {mean }}$ threshold in the region of $1.4-1.6 \times 10^{-3}$ seconds $/ \mathrm{mm}^{2}$ for $1 \mathrm{p} 19 \mathrm{q}$ genotyping. ${ }^{31,32}$ However, similar to the reduced specificity of elevated perfusion (blood volume), which may be observed in low-grade oligodendrogliomas, erroneously low ADC values can occur in this tumor type despite its relatively good prognosis. A potential influence from extracellular matrix components is probable. ${ }^{33}$ It is also noteworthy that measurements in calcified tumor components may underestimate $\mathrm{ADC}$ values and should be avoided.

From our results, it appears that $\mathrm{ROI} \mathrm{ADC}_{\text {mean }}$ and $\mathrm{rADC}_{\text {mean }}$ are slightly superior to minimum ROI ADC measurements for IDH genotyping of WHO grade II and III gliomas. Similarly, Han et $\mathrm{al}^{34}$ investigated the variability of ADC values according to the ROI technique for glioma grading, with the mean ADC value of single-round ROI showing the highest effect size (0.72) and the greatest AUC (0.872), being superior to minimum measurements for the identification of high-grade gliomas. Within the aforementioned study, minimum ADC values also differed significantly between whole-volume and single-round ROI placements $(P=.003),{ }^{34}$ indicating that these are not interchangeable.

It has been shown that volumetric tumor diffusivity analysis is not necessarily superior to ROI placements, for example, for WHO grading. ${ }^{35}$ In 2 recent studies using ADC for $\mathrm{H} 3 \mathrm{~K} 27 \mathrm{M}$ histone-mutant glioma characterization, only the study using ROI measurements was predictive of genotype. ${ }^{36,37}$

It could be hypothesized that the previously reported lower accuracy of ADC for WHO grade IV glioblastoma IDH typing ${ }^{38}$ could be related to the foci of necrosis. However, in our current study, the best prediction of $I D H$ status for such masses was achieved using VOI $\mathrm{rADC}_{\text {mean }}$ values derived from segmentation inclusive of necrosis, as opposed to ROI measurement in solid lesion components. Indeed, our data suggest that partially necrotic tumors may benefit from a volumetric diffusivity (VOI $\left.\mathrm{rADC}_{\text {mean }}\right)$ assessment, but the small patient number $(n=23)$ in this subgroup is a limitation of our research. Furthermore, it is possible that in some cases of necrotic tumors, limited tissue sampling resulted in a WHO grade II and III diagnosis instead of glioblastoma.

Imperfections in the volumetric image registration at glioma margins due to ADC map distortion from susceptibility gradients and eddy current effects, which are not visible in the T2-weighted image data, could have contributed to volumetric minimum ADC measurements performing less well in our research.

While the binary discrimination of $I D H$ wild-type from $I D H$ mutant gliomas is imperfect, noninvasive identification of early glioblastoma stages could help prioritize tissue sampling in such circumstances in which observational management is initially favored or when waiting times to surgery could result in a diagnostic delay.

\section{CONCLUSIONS}

Regional diffusivity measurements are noninferior and are possibly preferable to volumetric histogram analysis for $I D H$ status prediction of macroscopically solid WHO grade II and III gliomas. ROI $\mathrm{rADC}_{\text {mean }}$ calculation is rapid and scanner-independent, thus easily introduced into clinical reporting. Partially necrotic, rim-enhancing lesions are unsuitable for ROI assessment and may benefit from volumetric ADC quantification for genotyping.

Disclosures: Stefanie C. Thust-RELATED: Grant: National Institute of Health Research/Biomedical Research Center funding scheme, Comments: University College London/University College London Hospitals receive proportional funding through the UK National Institute of Health Research/Biomedical Research Center funding scheme. No specific grant number is associated with the presented research.* Hans Rolf Jäger-UNRELATED: Royalties: payment by Springer of 11000 , Comments: payment for co-editing the textbook Clincal Neuroradiology, published by Springer in 2019. *Money paid to the institution.

\section{REFERENCES}

1. Brat DJ, Verhaak RG, Aldape KD, et al; Cancer Genome Atlas Research Network. Comprehensive, integrative genomic analysis of diffuse lower-grade gliomas. $N$ Engl J Med 2015;372:2481-98 CrossRef Medline

2. Louis DN, Perry A, Reifenberger G, et al. The 2016 World Health Organization Classification of Tumors of the Central Nervous System: a summary. Acta Neuropathol 2016;131:803-20 CrossRef Medline

3. Stichel D, Ebrahimi A, Reuss D, et al. Distribution of EGFR amplification, combined chromosome 7 gain and chromosome 10 loss, and TERT promoter mutation in brain tumors and their potential for the reclassification of $I D H$ wild type astrocytoma to glioblastoma. Acta Neuropathol 2018;136:793-803 CrossRef Medline

4. Tesileanu CM, Dirven L, Wijnenga MM, et al. Survival of diffuse astrocytic glioma, IDH1/2-wild type, with molecular features of glioblastoma, WHO grade IV: a confirmation of the cIMPACT-NOW criteria. Neuro Oncol 2020;22:515-23 CrossRef Medline

5. van den Bent MJ, Brandes AA, Taphoorn MJ, et al. Adjuvant procarbazine, lomustine, and vincristine chemotherapy in newly diagnosed anaplastic oligodendroglioma: long-term follow-up of EORTC brain tumor group study 26951. J Clin Oncol 2013;31:34450 CrossRef Medline

6. Wijnenga MM, French PJ, Dubbink HJ, et al. The impact of surgery in molecularly defined low-grade glioma: an integrated clinical, radiological, and molecular analysis. Neuro Oncol 2018;20:103-12 CrossRef Medline

7. Kreth FW, Thon N, Simon M, et al. Gross total but not incomplete resection of glioblastoma prolongs survival in the era of radiochemotherapy. Ann Oncol 2013;24:3117-23 CrossRef Medline

8. Li YM, Suki D, Hess K, et al. The influence of maximum safe resection of glioblastoma on survival in 1229 patients: can we do better than gross-total resection? J Neurosurg 2016;124:977-88 CrossRef Medline 
9. Mazurowski MA, Desjardins A, Malof JM. Imaging descriptors improve the predictive power of survival models for glioblastoma patients. Neuro Oncol 2013;15:1389-94 CrossRef Medline

10. Hyare H, Rice L, Thust S, et al. Modelling MR and clinical features in grade II/III astrocytomas to predict IDH mutation status. Eur J Radiol 2019;114:120-27 CrossRef Medline

11. Thust SC, Heiland S, Falini A, et al. Glioma imaging in Europe: a survey of 220 centres and recommendations for best clinical practice. Eur Radiol 2018;28:3306-17 CrossRef Medline

12. Patterson DM, Padhani AR, Collins DJ. Technology insight: water diffusion MRI-a potential new biomarker of response to cancer therapy. Nat Clin Pract Oncol 2008;5:220-33 CrossRef Medline

13. Leu K, Ott GA, Lai A, et al. Perfusion and diffusion MRI signatures in histologic and genetic subtypes of WHO grade II-III diffuse gliomas. J Neurooncol 2017;134:177-88 CrossRef Medline

14. Xing Z, Yang X, She D, et al. Noninvasive assessment of IDH mutational status in World Health Organization grade II and III astrocytomas using DWI and DSC-PWI combined with conventional MR imaging. AJNR Am J Neuroradiol 2017;38:1138-44 CrossRef Medline

15. Wasserman JK, Nicholas G, Yaworski R, et al. Radiological and pathological features associated with IDH1-R132H mutation status and early mortality in newly diagnosed anaplastic astrocytic tumours. PLoS One 2015;10:e123890 CrossRef Medline

16. Liu T, Cheng G, Kang X, et al. Noninvasively evaluating the grading and IDH1 mutation status of diffuse gliomas by three-dimensional pseudo-continuous arterial spin labeling and diffusion-weighted imaging. Neuroradiology 2018;60:693-702 CrossRef Medline

17. Jaunmuktane Z, Capper D, Jones DTW, et al. Methylation array profiling of adult brain tumours: diagnostic outcomes in a large, single centre. Acta Neuropathol Commun 2019;7:24 CrossRef Medline

18. Reuss DE, Sahm F, Schrimpf D, et al. ATRX and IDH1-R132H immunohistochemistry with subsequent copy number analysis and IDH sequencing as a basis for an "integrated" diagnostic approach for adult astrocytoma, oligodendroglioma and glioblastoma. Acta Neuropathol 2015;129:133-46 CrossRef Medline

19. Pipe J. Pulse sequences for diffusion-weighted MRI. In: JohansenBerg H, Behrens TE, eds. Diffusion MRI. Academic Press; 2009:11-35

20. Grech-Sollars M, Hales PW, Miyazaki K, et al. Multi-centre reproducibility of diffusion MRI parameters for clinical sequences in the brain. NMR Biomed 2015;28:468-85 CrossRef Medline

21. Maynard J, Okuchi S, Wastling S, et al. World Health Organization grade II/III glioma molecular status: prediction by MRI morphologic features and apparent diffusion coefficient. Radiology 2020;296:111-21 CrossRef Medline

22. Thust SC, Hassanein S, Bisdas S, et al. Apparent diffusion coefficient for molecular subtyping of non-gadolinium-enhancing WHO grade II/III glioma: volumetric segmentation versus two-dimensional region of interest analysis. Eur Radiol 2018;28:3779-88 CrossRef Medline

23. Yushkevich PA, Piven J, Hazlett HC, et al. User-guided 3D active contour segmentation of anatomical structures: significantly improved efficiency and reliability. Neuroimage 2006;31:1116-28 CrossRef Medline

24. Jenkinson M, Bannister P, Brady M, et al. Improved optimization for the robust and accurate linear registration and motion correction of brain images. Neuroimage 2002;17:825-41 CrossRef Medline
25. Jenkinson M, Smith S. A global optimisation method for robust affine registration of brain images. Med Image Anal 2001;5:143-56 CrossRef Medline

26. Louis DN, Ohgaki H, Wiestler OD, et al. The 2007 WHO Classification of Tumours of the Central Nervous System. Acta Neuropathol 2007;114:97-109 CrossRef Medline

27. Hilario A, Ramos A, Perez-Nuñez A, et al. The added value of apparent diffusion coefficient to cerebral blood volume in the preoperative grading of diffuse gliomas. AJNR Am J Neuroradiol 2012;33:70107 CrossRef Medline

28. Sugahara T, Korogi $\mathrm{Y}$, Kochi M, et al. Usefulness of diffusionweighted MRI with echo-planar technique in the evaluation of cellularity in gliomas. J Magn Reson Imaging 1999;9:53-60 CrossRef Medline

29. Figini M, Riva M, Graham M, et al. Prediction of isocitrate dehydrogenase genotype in brain gliomas with MRI: single-shell versus multishell diffusion models. Radiology 2018;289:788-96 CrossRef Medline

30. Villanueva-Meyer JE, Wood MD, Choi BS, et al. MRI Features and IDH Mutational Status of Grade II Diffuse Gliomas: Impact on Diagnosis and Prognosis. American Journal of Roentgenology 2018;210:621-28 CrossRef Medline

31. Johnson DR, Diehn FE, Giannini C, et al. Genetically defined oligodendroglioma is characterized by indistinct tumor borders at MRI. AJNR Am J Neuroradiol 2017;38:678-84 CrossRef Medline

32. Cui $Y$, Ma L, Chen X, et al. Lower apparent diffusion coefficients indicate distinct prognosis in low-grade and high-grade glioma. $J$ Neurooncol 2014;119:377-85 CrossRef Medline

33. Sadeghi N, Camby I, Goldman S, et al. Effect of hydrophilic components of the extracellular matrix on quantifiable diffusionweighted imaging of human gliomas: preliminary results of correlating apparent diffusion coefficient values and hyaluronan expression level. AJR Am J Roentgenol 2003;181:235-41 CrossRef Medline

34. Han X, Suo S, Sun Y, et al. Apparent diffusion coefficient measurement in glioma: Influence of region-of-interest determination methods on apparent diffusion coefficient values, interobserver variability, time efficiency, and diagnostic ability. J Magn Reson Imaging 2017;45:722-30 CrossRef Medline

35. Takano K, Kinoshita M, Arita H, et al. Influence of region-of-interest designs on quantitative measurement of multimodal imaging of MR non-enhancing gliomas. Oncol Lett 2018;15:7934-40 CrossRef Medline

36. Aboian MS, Tong E, Solomon DA, et al. Diffusion characteristics of pediatric diffuse midline gliomas with histone H3-K27M mutation using apparent diffusion coefficient histogram analysis. AJNR Am J Neuroradiol 2019;40:1804-10 CrossRef Medline

37. Chen $\mathrm{H}, \mathrm{Hu}$ W, He H, et al. Noninvasive assessment of $\mathbf{H 3} \mathbf{~ K 2 7 M}$ mutational status in diffuse midline gliomas using apparent diffusion coefficient measurements. Eur J Radiol 2019;114:15259 CrossRef Medline

38. Tan WL, Huang WY, Yin B, et al. Can diffusion tensor imaging noninvasively detect IDH1 gene mutations in astrogliomas? A retrospective study of 112 cases. AJNR Am J Neuroradiol 2014;35:92097 CrossRef Medline 